\title{
Recycling of flexible polyurethane foam by split-phase alcoholysis: identification of additives and alcoholyzing agents to reach higher efficiencies
}

\author{
Thomas Vanbergen, ${ }^{[a]}$ Isabel Verlent, ${ }^{[b]}$ Joke De Geeter, ${ }^{[b]}$ Bart Haelterman, ${ }^{[b]}$ Laurens Claes, ${ }^{[a]}$ and \\ Dirk De Vos*[a]
}

[a] Thomas Vanbergen, Dr. Laurens Claes, Prof. Dr. Dirk De Vos ${ }^{\star}$

Microbial and Molecular Systems, Centre for Membrane Separations, Adsorption, Catalysis and Spectroscopy (cMACS), KU Leuven

Celestijnenlaan 200F, 3001 Leuven, Belgium

E-mail: dirk.devos@kuleuven.be

[b] Dr. Isabel Verlent, Joke De Geeter, Dr. Bart Haelterman

Recticel NV, Damstraat 2, 9230 Wetteren, Belgium

Supporting information for this article is given via a link at the end of the document.

\begin{abstract}
Split-phase alcoholysis of flexible polyurethane (PU) foam yields an apolar phase containing the recycled polyether polyol, and a lower, polar phase of the alcoholyzing agent and aromatic compounds. However, multiple purification steps are required to render the polyether polyol suitable for synthesis of new flexible PU foams; the unfavorable mass balance limits industrial applications. In this work, 2-pyrrolidone was identified as a performant additive for accelerating the dissolution and depolymerization process. By applying a lactam to PU foam weight ratio of $0.1: 1$, the glycol to PU foam weight ratio can be decreased from $1.5: 1$ to only $0.5: 1$, without loss of purity or yield of the recycled polyether polyol. Diglycerol was discovered as a novel, promising alcoholyzing agent; it allows to recycle the polyether polyol in high purity $(97 \%)$ and excellent yields (98\%), and after a single washing with diglycerol, a sufficiently low hydroxyl value $(61 \mathrm{mg} \mathrm{KOH} / \mathrm{g})$ is reached. The recycled polyether polyol can replace the virgin polyether polyol $(48 \mathrm{mg} \mathrm{KOH} / \mathrm{g}$ ) for up to $50 \%$ in the synthesis of new flexible PU foams with effects on the foam quality that stay within the limits of generally accepted specifications. A first step towards the valorization of the lower phase was also taken by hydrolysis of the newly formed carbamates to toluenediamines, which are readily reintegrated in new PU foams.
\end{abstract}

\section{Introduction}

Polyurethanes (PU) are an important class of plastic materials with an annual worldwide production of around 20 Mton (2019). ${ }^{[1]}$ Thermoset polyurethanes account for the highest market share due to their high resilience, durability and versatility. These materials are generally divided into three types: flexible foams $(53 \%)$, rigid foams $(42 \%)$ and durable elastomers $(5 \%)$, with applications in mattresses, furniture, insulation materials, surface coatings and sealants. The ubiquitous presence of polyurethanes in consumer goods ultimately generates huge volumes of plastic waste, posing severe environmental problems. However, thermoset polyurethanes cannot be thermally reprocessed because of the high degree of cross-linking between the polymer chains. Moreover, state-of-the-art physical methods for recycling of flexible foams are not adequate for handling the available volumes of waste. For example, compression molding results in polyurethane materials of low quality and hence with limited market demand. [2] Therefore, alternative methods comprising depolymerization of polyurethane foams have been developed, most notably hydrolysis, acidolysis, aminolysis and alcoholysis. ${ }^{[3 a-}$ 1] Interestingly, alcoholysis with polyfunctional alcohols ('glycolysis') may result in a biphasic product mixture ('splitphase'), with the apolar polyether polyols in the upper phase, and the more polar alcoholyzing agent and aromatic compounds in the lower phase. If the polyether polyols are recovered with sufficient purity, they are potentially suitable reactants for the synthesis of new flexible foams. Split-phase alcoholysis seems therefore a preferred recycling option for flexible PU foams.

However, most reported split phase processes use large masses of alcoholyzing agent, typically $1.5 \mathrm{~kg}$ per kg PU foam. ${ }^{[4 a-c]} \mathrm{A}$ large excess of reagents like diethylene glycol or glycerol is needed to achieve sufficiently high reaction rates, but the use of a large mass of virgin chemicals sharply increases process cost and $\mathrm{CO}_{2}$ footprint, ${ }^{[3 h, 5]}$ and necessitates extensive purification to recover the excess reagent. Furthermore, the recovered polyether polyol is often contaminated with significant amounts of alcoholyzing agents like diethylene glycol or ethylene glycol, requiring purification, e.g. distillation or washing to reach sufficient purity. ${ }^{[4 a}$ 6] Similarly, after an alcoholysis with glycerol, a washing step with acidified water was required before the polyether polyol could be reused in flexible foams or elastomers. ${ }^{[7 a-c]}$ This is closely related to the need to reach a low hydroxyl number, which is a measure for the amount of hydroxyl groups, for the production of flexible foams. The hydroxyl number for a virgin polyether polyol is in the order of $50 \mathrm{mg} \mathrm{KOH} / \mathrm{g},{ }^{[4 \mathrm{~b}]}$ while the upper layer in a split phase alcoholysis often has values well over $130 \mathrm{mg} \mathrm{KOH} / \mathrm{g}$. Finally, the recovered polyether polyol should also be substantially free of aromatic amines, which can be formed by hydrolysis. ${ }^{[8 a-b]}$ These amines are toxic and strongly disturb the polymerization kinetics in a subsequent foaming.

The mass input of the alcoholyzing agent, and hence the amount of lower phase, for which so far reported valorization strategies are inadequate ${ }^{[9]}$, may be decreased by using an additive that ideally facilitates both the dissolution and the depolymerization of flexible PU foam. Lactams have been suggested to induce depolymerization of rigid or flexible PU foam, either pure or in mixtures with alcohols. ${ }^{[10 a-b]}$ However, a split phase process using a mixture of $\varepsilon$-caprolactam and ethylene glycol at $190^{\circ} \mathrm{C}$ yielded 
a recovered polyether polyol with a hydroxyl value of $154 \mathrm{mg}$ $\mathrm{KOH} / \mathrm{g}$, which clearly is unsuitable for foaming into flexible polyurethanes. ${ }^{[10 a-b]}$

In this work, we tackle the key challenges of PU alcoholysis, like mass input, purity of the polyol layer, and specifically, the hydroxyl value and reusability of the polyether polyol. Various alcoholyzing agents are evaluated for the chemolysis of toluene diisocyanate(TDI)-based flexible PU foams with low mass input of alcoholyzing agent, with particular attention for depolymerization rate, separation behavior and product purity. We study in detail the potential benefits of a lactam like 2-pyrrolidone for split-phase alcoholysis. Our objective is to identify novel alcoholyzing agents that have sufficient promise to simultaneously tackle all of the aforementioned challenges in alcoholysis of flexible PU foam. Finally, valorization of the lower phase is explored by hydrolysis in order to split the aromatic products to toluenediamines, which can be reconverted to building blocks for new PU foams.

\section{Results and Discussion}

\section{Benchmark alcoholysis with diethylene glycol}

As a benchmark, the alcoholysis of TDI-based flexible PU foam was first performed in diethylene glycol, applying a glycol to PU foam weight ratio of $1.5: 1$, with a $\mathrm{Bi}$ (III) neodecanoate catalyst, as a non-toxic alternative to tin compounds employed in state-of-theart alcoholysis. ${ }^{[11]}$ Bismuth compounds have been reported as very active catalysts in an alcoholysis model reaction; also in our preliminary experiments $\mathrm{Bi}(\mathrm{III})$ neodecanoate stood out as a particularly active catalyst (Table S3). ${ }^{[12]}$ After $75 \mathrm{~min}$ at $200{ }^{\circ} \mathrm{C}$, the PU foam flakes were completely dissolved in the process medium and the reaction was continued for $180 \mathrm{~min}$. It must be noted that a PU foam contains not only carbamates, but at least as many $N, N$-diarylurea functional groups, due to the addition of water in the foaming process. The depolymerization therefore proceeds both via alcoholysis of carbamate and of urea groups with diethylene glycol. This results in the formation of polyether polyol and aromatic amine moieties respectively; the alcoholyzing agent is thereby incorporated in a new carbamate functional

Scheme 1. Depolymerization of flexible PU foam by alcoholysis of carbamate and diarylurea groups with diethylene glycol. R'OH represents the polyether polyol.

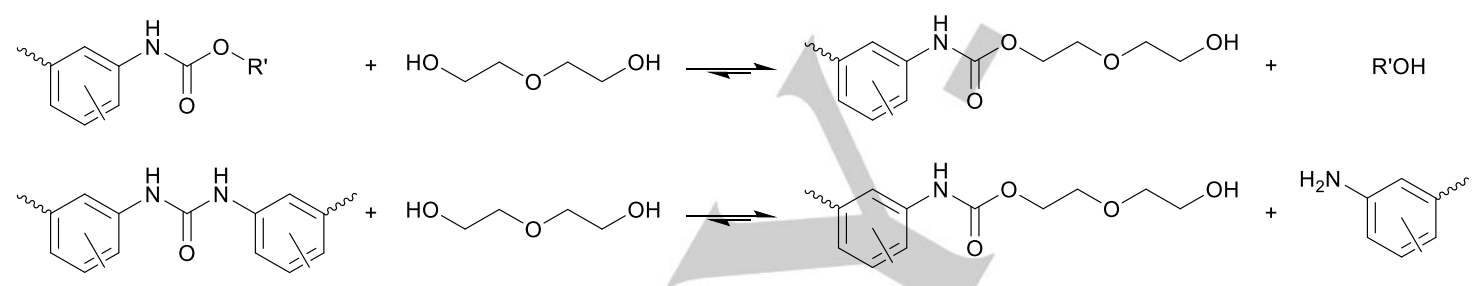

Table 1. ${ }^{1} \mathrm{H}$ NMR (DMSO-d $\mathrm{d}_{6}$ ) data for reference compounds and aromatic products generated by alcoholysis of flexible PU foam in diethylene glycol. ${ }^{[a]} \mathrm{R}$ represents a (2-hydroxyethoxy)ethyl moiety.

\begin{tabular}{|c|c|c|c|}
\hline Compound & Name & Molecular structure & Characteristic chemical shift(s), ppm \\
\hline \multirow{4}{*}{$\begin{array}{l}\text { Toluenediamines } \\
\text { (TDA) }\end{array}$} & \multirow{3}{*}{ 2,4-Toluenediamine } & & $5.86(\mathrm{~d}, \mathrm{~J}(\mathrm{H}, \mathrm{H})=2.1 \mathrm{~Hz}, 1 \mathrm{H}, \mathrm{Ar}-\mathrm{H})$ \\
\hline & & & $5.75(\mathrm{dd}, \mathrm{J}(\mathrm{H}, \mathrm{H})=7.3 \mathrm{~Hz}$ and $2.2 \mathrm{~Hz}, 1 \mathrm{H}, \mathrm{Ar}-$ \\
\hline & & & $\mathrm{H})$ \\
\hline & 2,6-Toluenediamine & & $5.93(\mathrm{~d}, \mathrm{~J}(\mathrm{H}, \mathrm{H})=8.0 \mathrm{~Hz}, 2 \mathrm{H}, \mathrm{Ar}-\mathrm{H})$ \\
\hline \multirow{10}{*}{$\begin{array}{c}\text { Toluene } \\
\text { aminocarbamates } \\
\text { (TAC) }\end{array}$} & \multirow{3}{*}{$\begin{array}{l}\text { 2-(2-Hydroxyethoxy)ethyl 5-amino-2- } \\
\text { methylphenylcarbamate }\end{array}$} & & $6.78(\mathrm{~m})$ \\
\hline & & & $6.61(\mathrm{~s})$ \\
\hline & & & $6.54(\mathrm{~m})$ \\
\hline & \multirow{2}{*}{$\begin{array}{l}\text { 2-(2-Hydroxyethoxy)ethyl 3-amino-4- } \\
\text { methylphenylcarbamate }\end{array}$} & & $6.47(\mathrm{t}, \mathrm{J}(\mathrm{H}, \mathrm{H})=7.0 \mathrm{~Hz})$ \\
\hline & & & $6.21(\mathrm{~d}, \mathrm{~J}(\mathrm{H}, \mathrm{H})=8.4 \mathrm{~Hz})$ \\
\hline & \multirow{2}{*}{$\begin{array}{l}\text { 2-(2-Hydroxyethoxy)ethyl 3-amino-2- } \\
\text { methylphenylcarbamate }\end{array}$} & & $6.02(\mathrm{t}, \mathrm{J}(\mathrm{H}, \mathrm{H})=5.9 \mathrm{~Hz})$ \\
\hline & & & $5.80(\mathrm{~d}, \mathrm{~J}(\mathrm{H}, \mathrm{H})=7.0 \mathrm{~Hz})$ \\
\hline & \multirow{3}{*}{$\begin{array}{l}\text { Ethyl 3-amino-2-methylphenylcarbamate } \\
\text { (reference) }\end{array}$} & & $6.78(\mathrm{~d}, \mathrm{~J}=8.2 \mathrm{~Hz}, 1 \mathrm{H}, \mathrm{Ar}-\mathrm{H})$ \\
\hline & & & $6.61(\mathrm{~d}, \mathrm{~J}=2.3 \mathrm{~Hz}, 1 \mathrm{H}, \mathrm{Ar}-\mathrm{H})$ \\
\hline & & & $6.21(\mathrm{~m}, \mathrm{~J}=2.30 \text { and } 8.20 \mathrm{~Hz}, 1 \mathrm{H}, \mathrm{Ar}-\mathrm{H})^{[13 \mathrm{a}]}$ \\
\hline \multirow{8}{*}{$\begin{array}{c}\text { Toluene } \\
\text { dicarbamates } \\
\text { (TDC) }\end{array}$} & \multirow{3}{*}{$\begin{array}{c}\text { Bis(ethyl) 4-methyl-phenylene-1,3- } \\
\text { dicarbamate (reference) }\end{array}$} & & $7.49(\mathrm{~s}, 1 \mathrm{H}, \mathrm{Ar}-\mathrm{H})$ \\
\hline & & & $7.16(\mathrm{dd}, \mathrm{J}=2.1 \mathrm{~Hz}, 1 \mathrm{H}, \mathrm{Ar}-\mathrm{H})$ \\
\hline & & & $7.05(\mathrm{~d}, \mathrm{~J}=8.4 \mathrm{~Hz}, 1 \mathrm{H}, \mathrm{Ar}-\mathrm{H})^{[13 \mathrm{~b}]}$ \\
\hline & \multirow{2}{*}{$\begin{array}{l}\text { Bis(2-(2-hydroxyethoxy)ethyl) 4-methyl- } \\
\text { phenylene-1,3-dicarbamate }\end{array}$} & \multirow{5}{*}{$\prod_{0}^{1}$} & $7.49(\mathrm{~s})$ \\
\hline & & & $7.16(\mathrm{~d}, \mathrm{~J}(\mathrm{H}, \mathrm{H})=8.2 \mathrm{~Hz})$ \\
\hline & \multirow{3}{*}{$\begin{array}{l}\text { Bis(2-(2-hydroxyethoxy)ethyl) 2-methyl- } \\
\text { phenylene-1,3-dicarbamate }\end{array}$} & & $7.12(s)$ \\
\hline & & & $7.05(\mathrm{~d}, \mathrm{~J}(\mathrm{H}, \mathrm{H})=8.4 \mathrm{~Hz})$ \\
\hline & & & $7.03(\mathrm{~s})$ \\
\hline
\end{tabular}




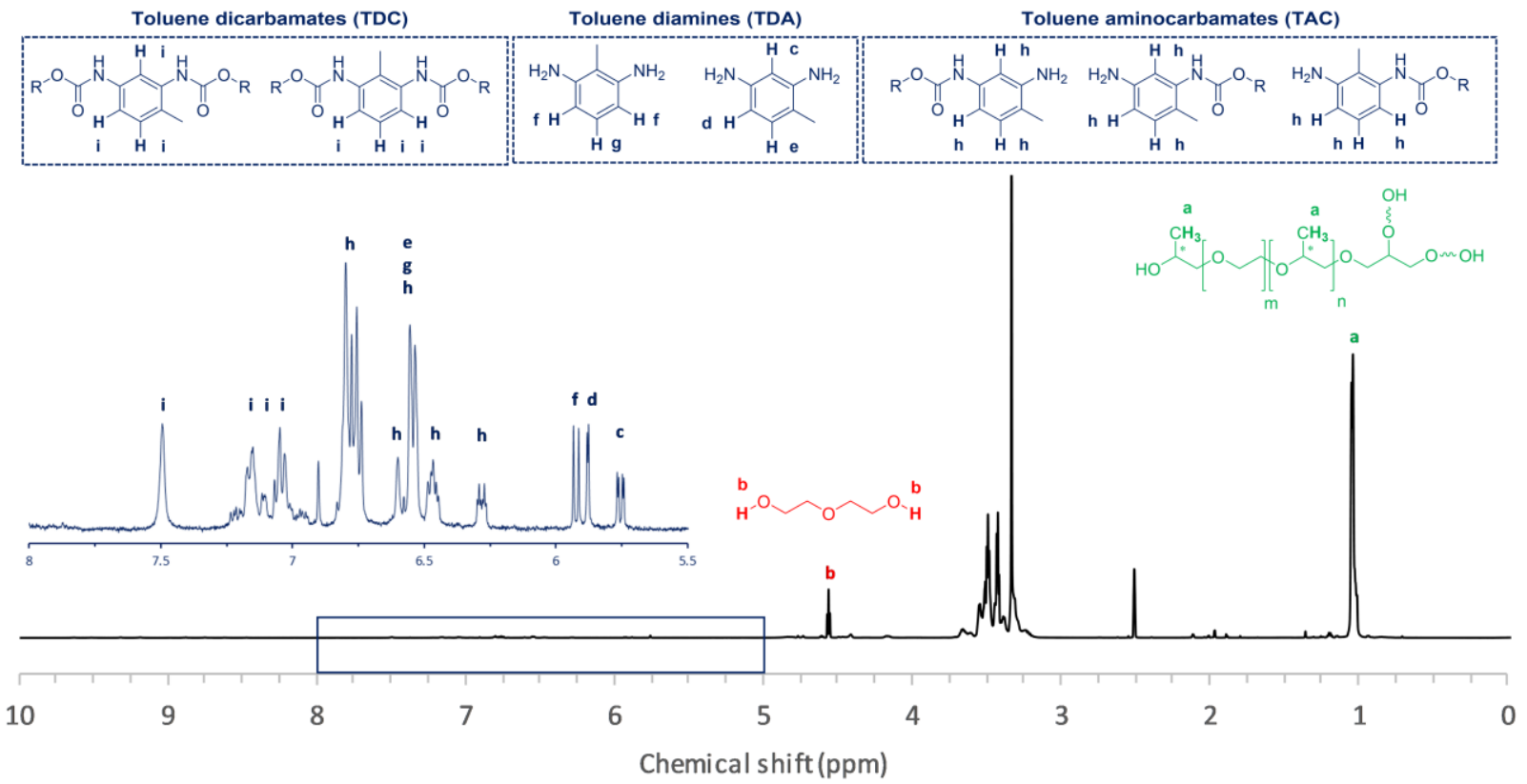

Figure 1. ${ }^{1} \mathrm{H}$ NMR $\left(600 \mathrm{MHz}\right.$, DMSO- $\mathrm{d}_{6}$ ) spectra of the upper phase after split-phase alcoholysis of flexible PU foam in diethylene glycol. Conditions: PU foam (4 $\mathrm{g}$ ), diethylene glycol (1.5:1 PU), BK850 catalyst $(0.01: 1 \mathrm{PU}), 200{ }^{\circ} \mathrm{C}, 180 \mathrm{~min}$ of depolymerization. The characteristic signals are assigned to the corresponding protons (highlighted in bold). $R$ represents a (2-hydroxyethoxy)ethyl moiety.

group (Scheme 1). After alcoholysis, the product mixture separated into a light brown upper phase (UP) and a darker lower phase (LP).

A method was developed to quantitatively determine the composition of each phase by ${ }^{1} \mathrm{H}$ NMR spectroscopy (14.1 T), by integration of the signals of characteristic protons, and based on comparison with the pure compounds measured in the same DMSO- $d_{6}$ solvent (Table 1 and Figure 1 ). The polyether polyol was quantified using a characteristic signal at $1.05 \mathrm{ppm}$ of the methyl protons in the propylene oxide (PO) units (Figure 1). For diethylene glycol, a characteristic signal of the hydroxyl protons at $4.55 \mathrm{ppm}$ was used. Regarding the aromatics, the analysis is facilitated by the fact that all arenes in the mixture bear three $\mathrm{H}$ atoms on the ring, and that they all originate from the same 2,4and 2,6-TDI precursors. 2,4-Toluenediamine and 2,6toluenediamine were quantified based on well-isolated signals of their aryl protons at respectively, 5.75, 5.86 and $5.93 \mathrm{ppm}$. Apart from the signals of the toluenediamines, the remaining signals between 6.2 and $6.92 \mathrm{ppm}$ were assigned to aryl protons on toluene aminocarbamates (TAC), the slightly higher chemical shift being due to the electron withdrawing effect of the carbamate group. Finally, the signals between 6.95 and $7.55 \mathrm{ppm}$ were assigned to the aryl protons of toluene dicarbamate isomers (TDC); the even higher chemical shifts are due to the presence of two carbamate groups. These trends of the chemical shifts in the mono- and dicarbamates were confirmed by comparison with the spectra of corresponding mono- and diethylcarbamates. ${ }^{[13 a-b]}$

This ${ }^{1} \mathrm{H}$ NMR method was used to quantitatively analyze both the upper and the lower phase obtained with various masses of diethylene glycol (DEG, Table 2). For a 1.5:1 glycol to PU weight ratio, it was found that the upper phase was enriched in the polyether polyol (75 wt\%), but also contained a substantial amount of diethylene glycol (18 wt\%) and aromatic compounds (6.9 wt\%) (Table 2, entry 1). Although the lower phase was enriched in diethylene glycol (59 wt\%) and aromatic compounds (20 wt\%), the polyether polyol was also present in a substantial

Table 2. Analysis of upper phases (UP) and lower phases (LP) obtained after split-phase alcoholysis of flexible PU foam in diethylene glycol (DEG). ${ }^{[a]}$ TDC $=$ toluenedicarbamate, TAC = tolueneaminocarbamate, TDA = toluenediamine.

\begin{tabular}{|c|c|c|c|c|c|c|c|c|c|c|c|c|}
\hline Entry & $\begin{array}{c}\text { DEG:PU } \\
\text { weight ratio }\end{array}$ & $\begin{array}{c}\text { Dissolution } \\
\text { time (min) }\end{array}$ & Phase & $\begin{array}{l}\text { Mass } \\
(\mathrm{g})\end{array}$ & $\begin{array}{c}\text { Polyether } \\
\text { polyol } \\
(w t \%)\end{array}$ & $\begin{array}{c}\text { Polyether } \\
\text { polyol } \\
\text { Yield }^{[b]}(\%)\end{array}$ & $\begin{array}{l}\text { TDC } \\
\text { (wt\%) }\end{array}$ & $\begin{array}{l}\text { TAC } \\
\text { (wt\%) }\end{array}$ & $\begin{array}{c}\text { TDA } \\
\text { (wt\%) }\end{array}$ & $\begin{array}{c}\text { DEG } \\
\text { (wt\%) }\end{array}$ & $\begin{array}{l}\text { Lactam } \\
(w t \%)\end{array}$ & $\begin{array}{c}\text { Hydroxyl } \\
\text { value }{ }^{[c]} \\
(\mathrm{mg} \mathrm{KOH} / \mathrm{g})\end{array}$ \\
\hline \multirow{2}{*}{1} & \multirow{2}{*}{$1.5: 1$} & \multirow{2}{*}{75} & UP & 2.8 & 75 & 81 & 2.1 & 3.6 & 1.2 & 18 & - & 248 \\
\hline & & & LP & 7.2 & 21 & - & 7.3 & 9.8 & 2.6 & 59 & - & 693 \\
\hline \multirow{2}{*}{2} & \multirow{2}{*}{$1: 1$} & \multirow{2}{*}{80} & UP & 2.4 & 80 & 73 & 1.0 & 1.9 & 0.9 & 16 & - & 223 \\
\hline & & & LP & 5.6 & 24 & - & 7.6 & 7.9 & 2.6 & 58 & - & 679 \\
\hline \multirow{2}{*}{3} & \multirow{2}{*}{$0.5: 1$} & \multirow{2}{*}{150} & UP & 0.7 & 83 & 21 & 1.9 & 2.9 & 1.4 & 11 & - & 179 \\
\hline & & & LP & 5.3 & 61 & - & 7.6 & 6.1 & 2.5 & 23 & - & 312 \\
\hline \multirow{2}{*}{4} & \multirow{2}{*}{$0.5: 1^{[d]}$} & \multirow{2}{*}{40} & UP & 1.8 & 82 & 66 & 1.2 & 3.1 & 1.5 & 9 & 3.1 & $172(160)$ \\
\hline & & & LP & 4.6 & 27 & - & 11.6 & 14.8 & 4.2 & 35 & 8.2 & 497 \\
\hline
\end{tabular}

[a] Conditions: PU foam (4 g), DEG (2-6 g), BK850 catalyst $(0.01: 1 \mathrm{PU}), 200^{\circ} \mathrm{C}, 180 \mathrm{~min}$ of depolymerization. [b] Yield $=\%$ mass recovery of the polyether polyol with respect to the amount originally used in foam synthesis. [c] Theoretical value based on ${ }^{1} \mathrm{H}$ NMR analysis; experimental value, measured by titration, between parentheses. [d] 2-Pyrrolidone (0.1:1) was used as an additive. 


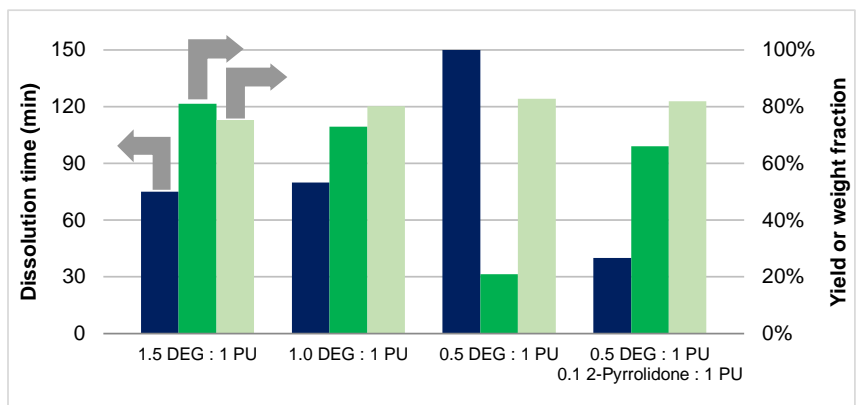

- dissolution time - polyether polyol yield polyether polyol weight fraction

Figure 2. Analysis of the upper phases obtained after split-phase alcoholysis of flexible PU foam in diethylene glycol (DEG). Conditions: PU foam (4 g), DEG, 2-pyrrolidone, BK850 catalyst $(0.01: 1 \mathrm{PU}), 200^{\circ} \mathrm{C}, 180 \mathrm{~min}$ of depolymerisation.

amount (21 wt\%). In an attempt to reduce the mass input of alcoholyzing agent, the reaction was performed at a glycol to PU foam weight ratio of 1:1 (Table 2, entry 2). The dissolution of PU foam was completed within $80 \mathrm{~min}$ and a phase separation was observed after $180 \mathrm{~min}$ of depolymerization. Although the polyether polyol content of the upper phase had increased to 80 wt $\%$, the yield decreased from $81 \%$ to $73 \%$ (Figure 2). Upon further reduction of the glycol to PU foam weight ratio to $0.5: 1$, the dissolution of PU foam proceeded much more slowly (150 min) and a poor yield of $21 \%$ was obtained (Table 2, entry 3 ). These results show that the depolymerization of polyurethane proceeds at a much slower rate at lower mass input of diethylene glycol.

\section{Accelerating the alcoholysis}

Next, 2-pyrrolidone was employed as an additive to accelerate the dissolution and depolymerization of polyurethane in the process medium (Table 2, entry 4). By applying a glycol to PU foam weight ratio of $0.5: 1$, and a lactam to $\mathrm{PU}$ foam weight ratio of $0.1: 1$, the dissolution of PU foam was completed within 40 min and after reaction a substantial upper phase was obtained. The polyether polyol content of the upper phase was $82 \mathrm{wt} \%$, which is similar to the alcoholysis experiment in the absence of 2-pyrrolidone (entry 3 ), but the yield increased to $66 \%$, indicating that the depolymerization proceeded to a much higher extent. These observations can be attributed to the participation of 2-pyrrolidone in hydrogen bonding interactions, which can be rationalized in terms of the Kamlet-Taft parameters. The hydrogen bond acidity $(\alpha)$ and hydrogen bond basicity $(\beta)$ of 2-pyrrolidone are respectively 0.38 and $0.76,{ }^{[14]}$ reflecting that this lactam can act both as donor and acceptor of hydrogen bonds. In this way 2pyrrolidone facilitates nucleophilic addition-elimination reactions at the carbamate and urea groups. 2-Pyrrolidone and other lactams have indeed been suggested earlier to facilitate the depolymerization of polyurethanes at $150-250{ }^{\circ} \mathrm{C} \cdot{ }^{[10 \mathrm{a}-\mathrm{b}]}$

The upper phase of each alcoholysis experiment was further characterized by calculating a theoretical hydroxyl value, based on quantitative analysis of the ${ }^{1} \mathrm{H}$ NMR spectra (Table 2). When the depolymerization was performed at glycol to PU foam weight ratios of $1.5: 1$ or $1: 1$, the hydroxyl values were calculated at 248 $\mathrm{mg} \mathrm{KOH} / \mathrm{g}$ and $223 \mathrm{mg} \mathrm{KOH} / \mathrm{g}$, respectively (entries 1-2). These values are very high compared to the virgin polyether polyol (viz. $48 \mathrm{mg} \mathrm{KOH} / \mathrm{g}$ ), which is due to the large fraction of glycol in the upper phase. Such a large hydroxyl value renders the polyol unsuitable for the production of a flexible foam. The hydroxyl value somewhat decreased when the reaction was performed with a lower mass input of diethylene glycol; e.g. a value of 172 $\mathrm{mg} \mathrm{KOH} / \mathrm{g}$ was found after alcoholysis with a glycol to PU foam weight ratio of $0.5: 1$ and a 2-pyrrolidone to $\mathrm{PU}$ foam weight ratio of $0.1: 1$ (entry 4). Moreover, this value is in fair agreement with the experimental hydroxyl value of $160 \mathrm{mg} \mathrm{KOH} / \mathrm{g}$, which was measured by acid-base titration.

\section{Effect of alcoholyzing agent on polyol hydroxyl number}

In view of the high hydroxyl numbers, additional purification steps would be required to render the polyether polyol recovered from diethylene glycol alcoholysis suitable for the production of new flexible PU foams. In an attempt to increase the purity of the polyether polyol, other commercially available alcoholyzing agents were evaluated under the optimized conditions for splitphase alcoholysis, viz. with a 'glycol' to PU foam weight ratio of $0.5: 1$ and a 2-pyrrolidone to PU foam weight ratio of $0.1: 1$. The polarity of the alcoholyzing agent was systematically varied, e.g. by increasing the number of alcohol functions from 2 to 4 . The dissolution of PU foam was complete within less than $45 \mathrm{~min}$ in ethylene glycol and diethylene glycol, whereas at least $140 \mathrm{~min}$ were required for the same purpose in glycerol, diglycerol (technical grade containing a,a-diglycerol $(<90 \%)$ ) and pentaerythritol. The dissolution proceeded more slowly in more polar alcoholyzing agents. This can be attributed to the poor wetting of PU foam flakes. It must be noted that the addition of 2 pyrrolidone to pentaerythritol results in melting-point depression, rendering the reaction mixture liquid at around $150^{\circ} \mathrm{C}$ and allowing for wetting of the PU foam flakes. After alcoholysis, a clear phase separation was observed for all glycols tested. Qualitative GPC analyses of the upper phases showed the presence of the free polyether polyol in all cases, proving that complete depolymerization was achieved (Figure 3). Again, more precise quantitative information could be gathered by ${ }^{1} \mathrm{H}$ NMR analysis. This shows that the polyether polyol content of the upper phases varied between $82 \mathrm{wt} \%$, for reaction with diethylene glycol, and $96 \mathrm{wt} \%$, for diglycerol (Table 3, Figure 4). The major impurities in the upper phase are the alcoholyzing agent, aromatic compounds and some 2-pyrrolidone.

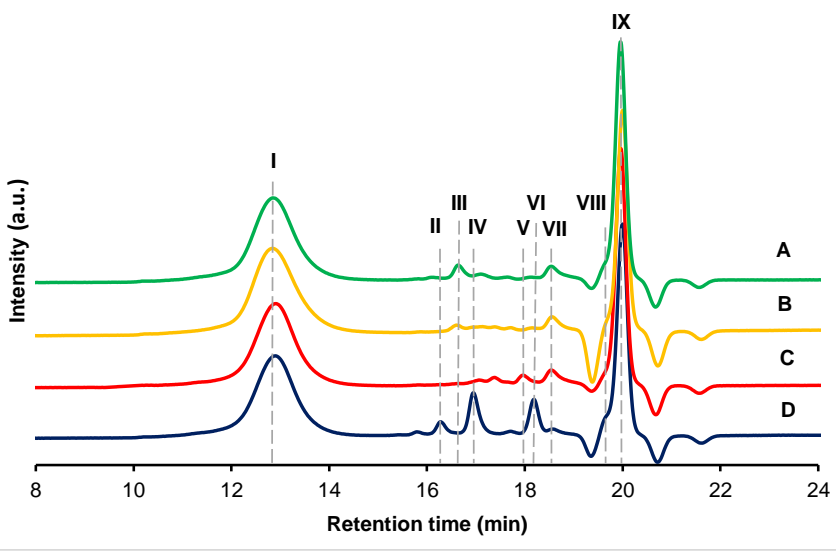

Figure 3. GPC chromatograms of the upper phases obtained by split-phase alcoholysis of flexible PU foam in different alcohols: (A) pentaerythritol, (B) diglycerol, (C) glycerol, (D) diethylene glycol. Conditions: PU foam $(4 \mathrm{~g})$, alcohol (0.5:1 PU), 2-pyrrolidone (0.1:1 PU), BK850 catalyst $(0.01: 1 \mathrm{PU}), 200^{\circ} \mathrm{C}, 180 \mathrm{~min}$ of depolymerization. Legend: (I) polyether polyol; (II-IV) aromatic products; (V-VI) alcoholyzing agent; (VII) 2,4- and 2,6-toluenediamine; (VIII) 2-pyrrolidone and (IX) toluene (internal standard). 
Table 3. Analysis of the upper phase obtained after split-phase alcoholysis of flexible PU foam in a mixture of various glycols and 2-pyrrolidone. [a]

\begin{tabular}{|c|c|c|c|c|c|c|c|c|c|c|c|}
\hline Entry & Alcohol & $\begin{array}{l}\text { Dissolution } \\
\text { time (min) }\end{array}$ & $\begin{array}{c}\text { Mass } \\
(\mathrm{g})\end{array}$ & $\begin{array}{c}\text { Polyether } \\
\text { polyol } \\
\text { (wt\%) }\end{array}$ & $\begin{array}{c}\text { Polyether } \\
\text { Polyol } \\
\text { Yield (\%) } \\
\end{array}$ & $\begin{array}{l}\text { TDC } \\
\text { (wt\%) }\end{array}$ & $\begin{array}{l}\text { TAC } \\
\text { (wt\%) }\end{array}$ & $\begin{array}{c}\text { TDA } \\
\text { (wt\%) }\end{array}$ & $\begin{array}{c}\text { Alcohol } \\
\text { (wt\%) }\end{array}$ & $\begin{array}{l}\text { Lactam } \\
\text { (wt\%) }\end{array}$ & $\begin{array}{c}\text { Hydroxyl } \\
\text { value }^{[\mathrm{b}]} \\
(\mathrm{mg} \mathrm{KOH} / \mathrm{g})\end{array}$ \\
\hline 1 & Diethylene glycol & 40 & 1.8 & 82 & 66 & 1.2 & 3.1 & 1.5 & 9.2 & 3.1 & $172(160)$ \\
\hline 2 & Ethylene glycol & 35 & 2.3 & 84 & 86 & 0.0 & 2.3 & 2.1 & 8.7 & 2.6 & 234 \\
\hline 3 & Glycerol & 180 & 1.7 & 92 & 70 & 0.0 & 0.0 & 2.9 & 3.0 & 1.9 & $133(124)$ \\
\hline 5 & Pentaerythritol & 140 & 1.3 & 93 & 53 & 0.2 & 1.0 & 2.9 & 0.4 & 2.5 & $89(81)$ \\
\hline
\end{tabular}

[a] Conditions: PU foam (4 g), alcohol (0.5:1 PU), 2-pyrrolidone (0.1:1 PU), BK850 catalyst (0.01:1 PU), $200^{\circ} \mathrm{C}, 180$ min of depolymerization. [b] Theoretical value based on ${ }^{1} \mathrm{H}$ NMR analysis; experimental hydroxyl value, measured by titration, between parentheses.

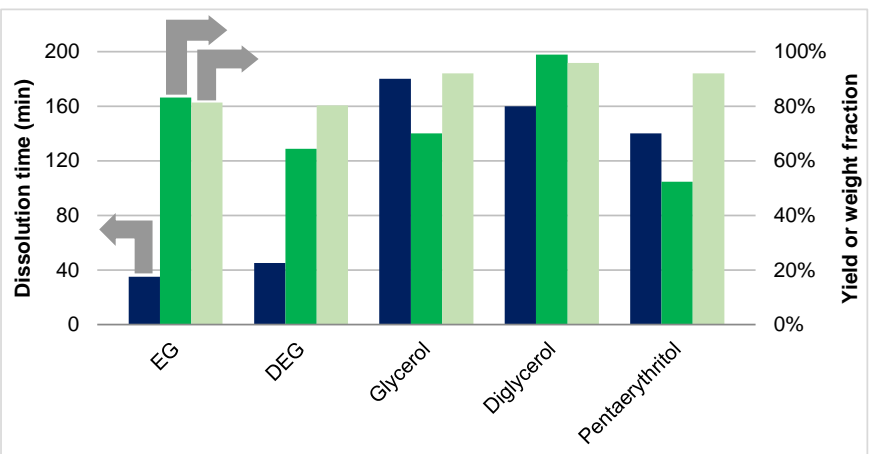

- dissolution time - polyether polyol yield polyether polyol weight fraction

Figure 4. Analysis of the upper phases obtained after split-phase alcoholysis of flexible PU foam in various alcoholyzing agents. Conditions: PU foam (4 g), alcoholyzing agent $(0.5: 1), 2$-pyrrolidone $(0.1: 1)$, BK850 catalyst $(0.01: 1), 200^{\circ} \mathrm{C}$, $180 \mathrm{~min}$ of depolymerisation.

Glycols such as diethylene glycol and ethylene glycol, containing $2-\mathrm{OH}$ groups, were present in rather high amounts of respectively $9.2 \mathrm{wt} \%$ and $8.7 \mathrm{wt} \%$. A more polar glycol such as glycerol, containing $3-\mathrm{OH}$ groups, was present in a small amount of $3.0 \mathrm{wt} \%$ while even more polar glycols such as diglycerol and pentaerythritol, containing $4-\mathrm{OH}$ groups, were present in very small amounts of respectively $0.3 \mathrm{wt} \%$ and $0.4 \mathrm{wt} \%$. A clear trend of stepwise decreasing glycol content in the upper phase can be observed with increasing number of $-\mathrm{OH}$ groups in the glycol. Similarly, the presence of toluene dicarbamates (TDC) and aminocarbamates (TAC) in the upper phase is also related to the nature of the 'glycol' that is incorporated into the carbamate group of these compounds; TDCs and TACs formed from a large, polar agent like diglycerol cause significantly less contamination of the upper phase. By contrast, the fraction of toluenediamines in the upper phase slightly increased when the alcoholysis was performed in highly polar alcoholyzing agents; from just $1.5 \mathrm{wt} \%$ in DEG (table 3, entry 1) to $2.9 \mathrm{wt} \%$ in both glycerol and pentaerythritol (entry 3 and 5). However, the fraction of toluenediamines in the upper phase from alcoholysis in diglycerol was surprisingly low at just $1.8 \mathrm{wt} \%$ (entry 4 ).

Summarizing, the separation behavior of the product mixture, and hence the purity of the polyether polyol in the upper phase, are strongly related to the polarity of the alcoholyzing agent. The theoretical hydroxyl value of the upper phase varied from $234 \mathrm{mg}$ $\mathrm{KOH} / \mathrm{g}$ for ethylene glycol, down to $74 \mathrm{mg} \mathrm{KOH} / \mathrm{g}$ for diglycerol. Alcoholysis in diglycerol and pentaerythritol allows to recover polyether polyols with hydroxyl values much closer to that of the virgin polyether polyol (viz. $48 \mathrm{mg} \mathrm{KOH} / \mathrm{g}$ ). Moreover, the polyether polyol was obtained in an excellent $99 \%$ yield in diglycerol (table 3 , entry 4). The mediocre yields obtained in other alcoholyzing agents can be explained by partial dissolution or emulsification of the polyether polyol in the lower phase. Besides, when the depolymerization did not proceed to completion, small polyurethane particles remained dispersed in the lower phase. Based on these observations diglycerol was identified as the most performant alcoholyzing agent, which allows to recycle polyether polyols from TDI-based polyurethanes with high purity and in high yield.

\section{Larger scale alcoholysis in diglycerol}

The split-phase alcoholysis of TDI-based flexible PU foam was subsequently carried out on a $400 \mathrm{~g}$ scale in diglycerol, under the optimized conditions (Table 4). The dissolution of PU foam was completed within 90 min, which is considerably faster than in the small scale reaction (Table 3, entry 4 ). The shorter dissolution time can be attributed to the gradual addition of PU foam flakes to the recipient and a better mixing of the process medium. However, the reaction time had to be extended from $180 \mathrm{~min}$ to $300 \mathrm{~min}$ to achieve complete depolymerization and to induce a clear phase separation. Afterwards, the upper phase was purified by applying a single washing step with diglycerol at $150{ }^{\circ} \mathrm{C}$. According to quantitative ${ }^{1} \mathrm{H}$ NMR analysis, the initial upper phase had already a very high polyether polyol content (97 wt\%), with small contaminations of toluenediamines and 2-pyrrolidone. After purification, the polyether polyol content could be increased up to 99 wt\% with a small amount of toluenediamines (0.5 wt\%)

Table 4. Analysis of the upper phase obtained after larger scale split-phase alcoholysis of flexible PU foam in a mixture of diglycerol and 2 -pyrrolidone. ${ }^{\text {[a] }}$

\begin{tabular}{|c|c|c|c|c|c|c|c|c|c|}
\hline Stage & $\begin{array}{c}\text { Polyether } \\
\text { polyol } \\
\text { (wt\%) }\end{array}$ & $\begin{array}{c}\text { Polyether } \\
\text { polyol } \\
\text { Yield (\%) } \\
\end{array}$ & $\begin{array}{c}\text { TDC } \\
\text { (wt\%) }\end{array}$ & $\begin{array}{c}\text { TAC } \\
(w t \%)\end{array}$ & $\begin{array}{c}\text { TDA } \\
(w t \%)\end{array}$ & $\begin{array}{l}\text { Diglycerol } \\
\text { (wt\%) }\end{array}$ & $\begin{array}{l}\text { Lactam } \\
\text { (wt\%) }\end{array}$ & $\begin{array}{l}\text { Hydroxyl value } \\
(\mathrm{mg} \mathrm{KOH} / \mathrm{g})^{[\mathrm{b}]}\end{array}$ & $\begin{array}{l}\text { Amine value } \\
(\mathrm{mg} \mathrm{KOH} / \mathrm{g})^{[\mathrm{b}]}\end{array}$ \\
\hline After purification & 99 & - & 0.0 & 0.3 & 0.5 & 0.4 & 0.0 & $58(61)$ & $5(10)$ \\
\hline
\end{tabular}

[a] Alcoholyis conditions: PU foam (400 g), diglycerol (0.5:1 PU), 2-pyrrolidone (0.1:1 PU), BK850 catalyst (0.01:1 PU), $200{ }^{\circ} \mathrm{C}, 300$ min of depolymerization. Purification conditions: upper phase $(254 \mathrm{~g})$, diglycerol $(1: 1 \mathrm{UP}), 150^{\circ} \mathrm{C}, 30 \mathrm{~min}$ of washing. [b] Theoretical value based on ${ }^{1} \mathrm{H}$ NMR analysis; experimental value, measured by titration, between parentheses. 
remaining. The hydroxyl value of the purified upper phase was calculated from NMR data at $58 \mathrm{mg} \mathrm{KOH} / \mathrm{g}$, which is again in good agreement with the value measured by titration, viz. $61 \mathrm{mg} \mathrm{KOH} / \mathrm{g}$ The recovered polyether polyol approximates the hydroxyl number of the virgin polyether polyol $(48 \mathrm{mg} \mathrm{KOH} / \mathrm{g})$. The amine number of the purified upper phase was calculated at $5 \mathrm{mg} \mathrm{KOH} / \mathrm{g}$ and measured at $10 \mathrm{mg} \mathrm{KOH} / \mathrm{g}$.

\section{Synthesis and characterisation of TDI-based flexible PU foams containing recycled polyether polyol}

The main goal of split-phase alcoholysis is to recycle the polyether polyol from end-of-life polyurethanes for the production of new flexible foams. In that respect the polyether polyols should meet several quality specifications: an average molecular weight between 2,000 and $6,000 \mathrm{~g} / \mathrm{mol}$, a functionality of 2 to 3 and a hydroxyl number between 28 and $100 \mathrm{mg} \mathrm{KOH} / \mathrm{g} \cdot{ }^{[7 a, 11]}$ The latter range is still fairly wide, and closer emulation of the original $\mathrm{OH}$ value would allow to reintegrate the polyol in the process with minimal protocol adjustments. The polyether polyol obtained by larger scale split-phase alcoholysis in diglycerol, with 2pyrrolidone as alcoholysis accelerator, and by subsequent purification (Table 4) was used to prepare new TDI-based flexible PU foams. To that end, the recycled polyether polyol was mixed with virgin polyether polyol in various proportions, ranging from $0 \%$ till $60 \%$ of recycled polyether polyol (Table 5 ).

The hydroxyl values of these polyether polyol mixtures vary between 48 and $56 \mathrm{mg} \mathrm{KOH} / \mathrm{g}$ and thus meet the required quality specifications. The reactivity during the foaming process was observed to be very similar for the five compositions and the resulting foams did not display noticeable defects (Figure 5). The foam density decreases very slightly with increasing amount of recycled polyol (Table 5); however this may be related to the decrease in air permeability. Lower air permeability indicates a more closed foam, retaining slightly more blowing gas $\left(\mathrm{CO}_{2}\right)$ and giving rise to slightly lower density foam. The decrease in air permeability with increasing amount of recycled polyol is most likely caused by the presence of diglycerol contaminations in the recycled polyol. The CLD hardness (see experimental section: characterization of flexible PU foams) was largely preserved with an initial slight increase from $3.6 \mathrm{kPa}$ in $\mathrm{V} 100$ to $3.8 \mathrm{kPa}$ in $\mathrm{V} 60$ $\mathrm{R} 40$ and subsequent decrease to $3 \mathrm{kPa}$ in V40-R60. The hysteresis loss displayed a slightly upward trend from $39 \%$ in $\mathrm{V} 100$ to $48 \%$ in $\mathrm{V} 60-\mathrm{R} 40$. The compression set $50 \%$ displayed a slight upward trend from 2.1 in V100 to 4.5 in V50-R50, indicating a slightly lower durability of the foam but remaining within the quality specifications for standard flexible foams. ${ }^{[16]}$ However, the compression set $50 \%$ increased substantially to 9.8 in V40-R60,

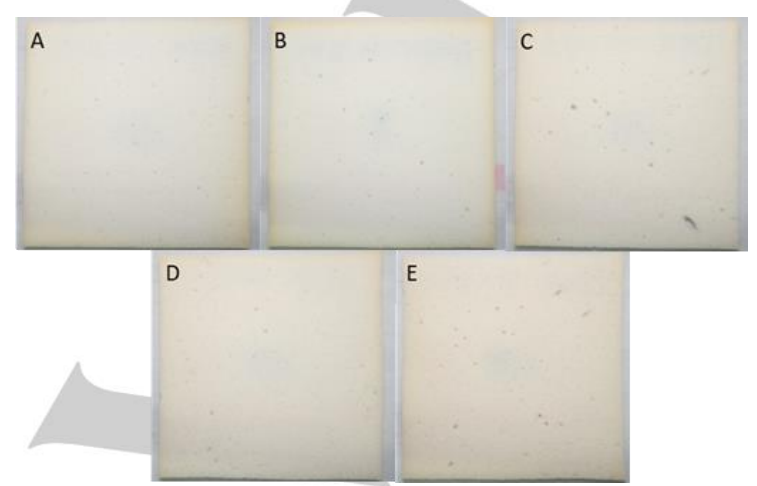

Figure 5. Visual observation of flexible PU foams prepared with different amounts of recycled polyether polyol: (A) $0 \%$ (reference); (B) 20\%; (C) $40 \%$; (D) $50 \%$ and (E) $60 \%$.
Table 5. Recycling of polyether polyol in the synthesis of flexible PU foams. [a] $V$ represents virgin and $R$ represents recycled

\begin{tabular}{|c|c|c|c|c|c|}
\hline & $\begin{array}{l}\text { V100 } \\
\text { [a] }\end{array}$ & $\begin{array}{l}\text { V80- } \\
\text { R20[a] }\end{array}$ & $\begin{array}{l}\text { V60- } \\
\text { R40[a] }\end{array}$ & $\begin{array}{l}\text { V50- } \\
\text { R50[a] }\end{array}$ & $\begin{array}{l}\text { V40- } \\
\text { R60[a] }\end{array}$ \\
\hline $\begin{array}{l}\text { Virgin polyether polyol (V; } \\
\mathrm{IOH}=48 \mathrm{mg} \mathrm{KOH} / \mathrm{g})(\mathrm{pbw})\end{array}$ & 100 & 80 & 60 & 50 & 40 \\
\hline $\begin{array}{l}\text { Recycled polyether polyol } \\
\begin{aligned} &(\mathrm{R} ; \mathrm{IOH}=61 \mathrm{mg} \mathrm{KOH} / \mathrm{g}) \\
&(\mathrm{pbw})\end{aligned}\end{array}$ & 0 & 0 & 40 & 50 & 60 \\
\hline $\begin{array}{c}\text { Hydroxyl number polyol } \\
\text { mixture }(\mathrm{mg} \mathrm{KOH} / \mathrm{g})\end{array}$ & 48 & 51 & 53 & 55 & 56 \\
\hline TDI80 (phpp) & 53.4 & 53.8 & 54.3 & 54.5 & 54.7 \\
\hline Water (phpp) & 4.22 & 4.22 & 4.22 & 4.22 & 4.22 \\
\hline $\begin{array}{l}\text { Additives (surfactant } \\
\text { catalysts) (phpp) }\end{array}$ & 1.74 & 1.74 & 1.74 & 1.74 & 1.74 \\
\hline Isocyanate index & 110 & 110 & 110 & 110 & 110 \\
\hline Reaction time (s) & 86 & 85 & 86 & 87 & 89 \\
\hline Density $\left(\mathrm{kg} / \mathrm{m}^{3}\right)$ & 25.0 & 24.7 & 24.5 & 24.3 & 24.3 \\
\hline Air permeability (I/dm².min) & 1387 & 978 & 547 & 256 & 111 \\
\hline CLD hardness $40 \%(\mathrm{kPa})$ & 3.6 & 3.7 & 3.8 & 3.5 & 3.0 \\
\hline Hysteresis $4^{\text {th }}$ curve (\%) & 39 & 39 & 42 & 44 & 48 \\
\hline Compression set $50 \%(\%)$ & 2.1 & 2.7 & 3.9 & 4.5 & 9.8 \\
\hline
\end{tabular}

indicating a substantially lower durability of the foam. Hence, one may conclude that the recycled polyether polyol can replace the virgin polyether polyol (48 $\mathrm{mg} \mathrm{KOH} / \mathrm{g}$ ) up to $50 \%$ with limited deterioration of the foam quality and mechanical properties. It should also be noted that the catalyst package was unaltered for all tested foams; however the foams with recycled polyol can be still made more open by fine-tuning the catalysts in the formulation. This would lower the retention of blowing gas, thereby increasing the foam density and improving its mechanical properties.

\section{Valorization of the lower phase by hydrolysis}

Valorization of the aromatic compounds in the lower phase is crucial for the atom economy and economic feasibility of the splitphase alcoholysis process. Specifically, if the mono- and dicarbamates in the isolated lower phase can be hydrolyzed, one would obtain the aromatics exclusively as diamines. This would constitute a uniform feedstock from which fresh PU can be produced, either via the traditional way involving isocyanate intermediates, or via innovative concepts using e.g. reactive carbonates, to form the so-called NIPUs (non-isocyanate polyurethanes). ${ }^{[17]}$ To exemplarily prove the concept of recovery of the diamines, the lower phase from alcoholysis in pentaerythritol and 2-pyrrolidone was subjected to a hydrolysis treatment with an excess of water at $200^{\circ} \mathrm{C}$ during $12 \mathrm{~h}$. The hydrolysis of toluene dicarbamates and aminocarbamates 
Scheme 2. Hydrolysis of the toluene dicarbamates and toluene aminocarbamates in the lower phase obtained by alcoholysis of flexible PU foam with pentaerythritol.<smiles>CC(CO)(CO)COC(=O)Nc1cccc(NC(=O)OCC(CO)(CO)CO)c1</smiles><smiles>CCOCCO</smiles>

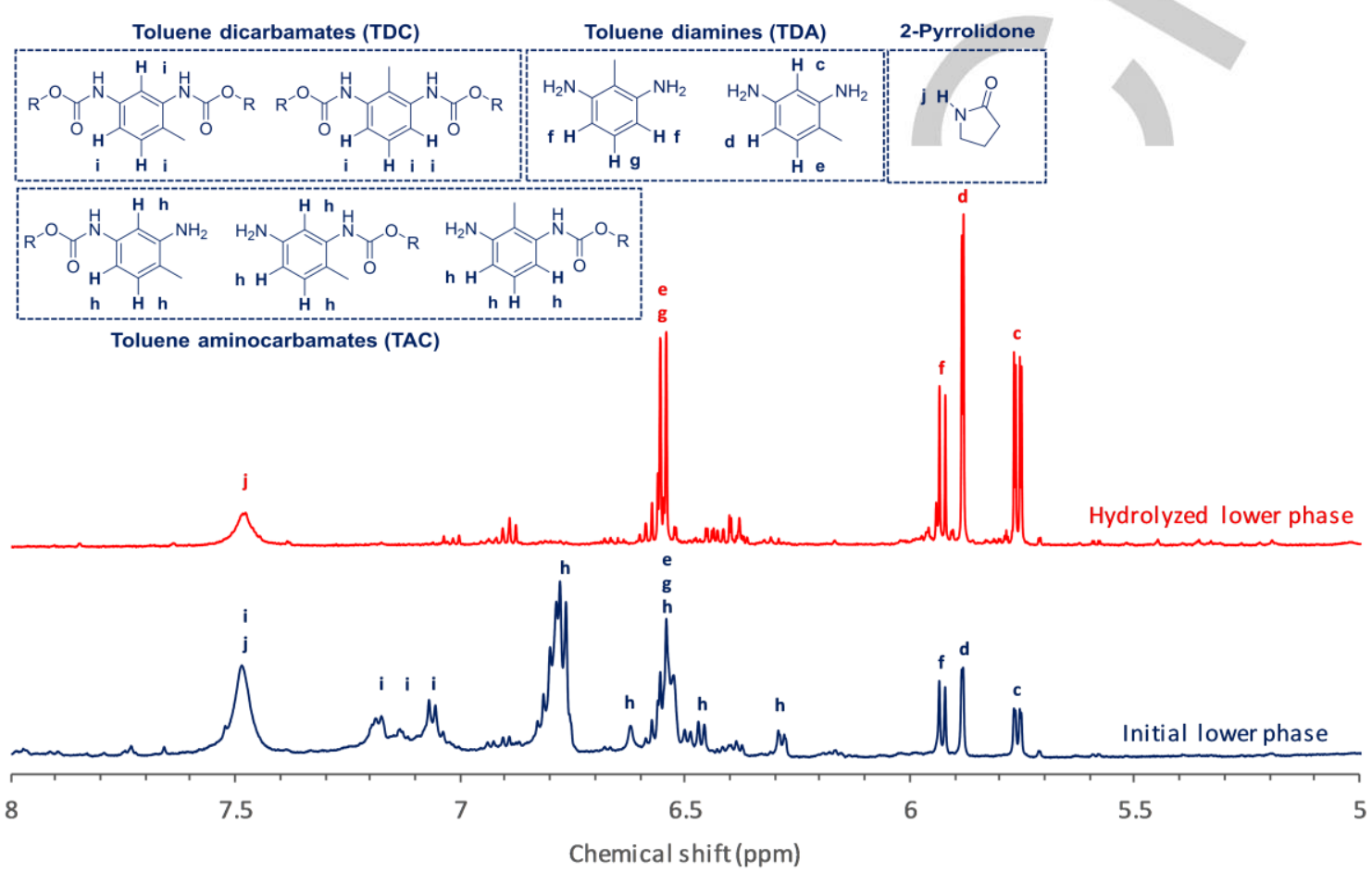

Figure 6. ${ }^{1} \mathrm{H}$ NMR $\left(600 \mathrm{MHz}\right.$, DMSO- $\left.\mathrm{d}_{6}\right)$ spectra of the aromatic region of the lower phase after split-phase alcoholysis of flexible PU foam in pentaerythritol and after hydrolysis. Alcoholysis conditions: PU foam (4 g), pentaerythritol (0.5:1 PU), 2-pyrrolidone (0.1:1 PU), BK850 catalyst (0.01:1 PU), $200{ }^{\circ} \mathrm{C}, 180$ min of depolymerization. Hydrolysis conditions: lower phase $(1 \mathrm{~g})$, water $(2: 1 \mathrm{LP}), 200{ }^{\circ} \mathrm{C}, 6 \mathrm{~h}$. The characteristic signals are assigned to the corresponding protons (highlighted in bold). $\mathrm{R}$ represents a 2,2,2-tris(hydroxymethyl)ethyl moiety

resulted in the formation of pentaerythritol, carbon dioxide and toluenediamines (Scheme 2). Comparison of the aromatics composition in the lower layer, before and after this hydrolysis treatment shows that the reaction is complete (figure 6); mainly signals corresponding to 2,4-toluenediamine and 2,6toluenediamine, in a $80: 20$ molar ratio, are seen in the spectrum.

\section{Conclusion}

Several key factors were identified to improve the split-phase alcoholysis of TDI-based flexible polyurethane foam. First, the addition of 2-pyrrolidone allowed to reduce the glycol to PU foam weight ratio from $1.5: 1$ to only $0.5: 1$, because this lactam facilitates the dissolution and depolymerization process by interacting with the hydrogen bonds within polyurethane. Moreover, diglycerol and pentaerythritol were identified as novel, promising alcoholyzing agents, because the polyether polyol could be recovered with a much higher purity and yield compared to reactions with state-of-the-art alcoholyzing agents such as diethylene glycol and glycerol. The split-phase alcoholysis in diglycerol allows to recycle the polyether polyol in high purity $(97 \%)$ and excellent yield (98\%), with a hydroxyl number of 80 $\mathrm{mg} \mathrm{KOH} / \mathrm{g}$, which was further decreased to $61 \mathrm{mg} \mathrm{KOH} / \mathrm{g}$ after a single washing step with diglycerol. The recycled polyether polyol could replace the virgin polyether polyol $(48 \mathrm{mg} \mathrm{KOH} / \mathrm{g}$ ) for up to $50 \%$ in the synthesis of new TDI-based flexible PU foams with limited effect on the foam quality and mechanical properties. Finally, the aromatic carbamates of the lower phase from alcoholysis in pentaerythritol were successfully converted to toluenediamines by a subsequent hydrolysis treatment as a key step to valorization of the lower phase.

\section{Experimental Section}

\section{Reagents}

A standard naked flexible polyurethane foam material, based on the polyether polyol Voranol 3322, was provided by Recticel (Belgium). Voranol 3322 (Dow) is a poly(propylene oxide)-block-poly(ethylene oxide) with a number-average molecular weight of $3500 \mathrm{~g} / \mathrm{mol}$ and a functionality of 3 alcohol groups, of which less than $10 \%$ are primary. This material has a polyol content of $55 \mathrm{wt} \%$ and a density of $25 \mathrm{~kg} / \mathrm{m}^{3}$. Bismuth(III) neodecanoate (BK850, Shepherd, 19.5-20.5 wt\% Bi) was used as a catalyst for PU depolymerization. Ethylene glycol (Carl Roth, 98\%), diethylene glycol (Carl Roth, 98\%), glycerol (Acros, 99\%), diglycerol (Inovyn, technical grade containing a,a-diglycerol <90\%) and 
pentaerythritol ( $\mathrm{TCl}, 98 \%)$ were used as alcoholyzing agents and 2pyrrolidone (Carl Roth, 99.5+\%) was applied as alcoholysis accelerator.

\section{Alcoholysis of flexible PU foams}

In a typical procedure, PU foam flakes $(12 \mathrm{~mm}$ diameter) were depolymerized in a mixture of the alcoholyzing agent (glycol to PU mass ratio of 0.5:1), 2-pyrrolidone (lactam to PU ratio of $0.1: 1$ ) and BK850 catalyst (catalyst to PU ratio of $0.01: 1$ ) at $200{ }^{\circ} \mathrm{C}$. Small scale reactions were performed in $22 \mathrm{~mL}$ screw cap glass vials which were equipped with a magnetic stirring rod at $200^{\circ} \mathrm{C}$. The PU foam flakes $(4 \mathrm{~g})$ were introduced according to dissolution and the reaction mixture was subsequently stirred at $600 \mathrm{rpm}$ during $180 \mathrm{~min}$ at $200^{\circ} \mathrm{C}$. Afterwards, the vials were subjected to centrifugation (2500 rpm, $10 \mathrm{~min}$ ) in order to improve the phase separation.

Larger scale reactions were performed in a $2 \mathrm{~L}$ three-necked round-bottom flask equipped with a mechanical stirrer, a reflux condenser and a conical funnel with an open spiral screw for automated addition of PU foam flakes (Figure S1). The alcoholysis was performed with diglycerol, 2-pyrrolidone and BK850 catalyst in a 0.5:0.1:0.01 mass ratio. PU foam flakes $(400 \mathrm{~g})$ were added over $90 \mathrm{~min}$ and the depolymerization was continued for 300 $\min$ at $200^{\circ} \mathrm{C}$. The isolated polyether polyol was centrifuged, subsequently purified by a washing step in diglycerol (glycol to UP ratio of $1: 1$ ) at $150^{\circ} \mathrm{C}$ for $30 \mathrm{~min}$ and finally centrifuged.

\section{Analytical techniques}

Both phases obtained after alcoholysis of TDI-based flexible PU foam were analyzed qualitatively by gel permeation chromatography (GPC) and quantitatively by nuclear magnetic resonance (NMR) spectroscopy. For GPC analysis, $0.5 \%$ of the upper phase and $0.13 \%$ of toluene (internal standard) were dissolved in tetrahydrofuran. The measurements were performed on a Waters chromatograph equipped with a PLgel $3 \mu \mathrm{m}$ MIXED-E (length $300 \mathrm{~mm}$ ) column, which is optimized for the resolution of small particles size of low molecular weight polymers, oligomers and additives, and a refractive index (RI) detector, using THF as eluent at $40^{\circ} \mathrm{C}$ (flow: $1 \mathrm{ml} / \mathrm{min}$ ). For ${ }^{1} \mathrm{H}$ NMR analysis, an aliquot of each phase $(0.020 \mathrm{~g})$ was dissolved in DMSO-d $\mathrm{d}_{6}(0.7 \mathrm{~mL})$. Spectra were recorded on a Bruker AMX $600 \mathrm{MHz}$ NMR spectrometer equipped with a TXI5 probe and a sample case. A pulse program was applied: p1 $15 \mu \mathrm{s}$, ns 64 , d1 $1.0 \mathrm{~s}$, aq $2.73 \mathrm{~s}$. Elongation of the relaxation time (d1) to $10 \mathrm{~s}$ did not influence the quantitative analysis. The purity of each phase was estimated via the hydroxyl and amine value, which were calculated based on ${ }^{1} \mathrm{H}$ NMR analysis (Supporting Information, Table S2) or measured by titration (ASTM E1899 and ISO 25761).

\section{Synthesis of TDI-based flexible PU foams containing recycled polyether polyol}

Flexible foaming tests were performed in standard formulations for flexible foams, based on a polyether polyol (viz. poly(propylene oxide)-blockpoly(ethylene oxide) with a functionality of 3 alcohol groups) combined with recycled polyether polyols. Toluene diisocyanate (TDI) 80:20 was used as isocyanate, water was employed as blowing agent and a standard catalyst and surfactant package was used to obtain flexible PU foams. The reaction time (or blow-off-time) to obtain these foam samples was recorded.

\section{Characterization of flexible PU foams}

The apparent density was measured according to the ISO 845 standard. The air permeability was measured according to the ISO 9237 standard. The air permeability $200 \mathrm{~Pa} 10 \mathrm{~mm}$ measures the velocity of an air flow passing perpendicularly through the sample (minimally $150 \times 150 \mathrm{~mm}$ ) with a thickness of $10 \mathrm{~mm}$ and a pressure drop of $200 \mathrm{~Pa}$. The compression load deflection (CLD) hardness $40 \%$ was measured according to the ISO $3386 / 1$ standard. The CLD hardness $40 \%$ is defined as the force required to compress a $100 \times 100 \times 50 \mathrm{~mm}$ piece of foam with a $200 \mathrm{~mm}$ diameter compression plate. The foam is compressed three times to $70 \%$, and after the third compression reading is taken at $40 \%$. The hysteresis (energy) loss is defined as the difference between the loading energy and the unloading energy expressed as a percentage of the loading energy. The compression set $50 \%$ was measured according to the ISO $1856 \mathrm{~A}$ standard The compression set $50 \%$ measures the permanent changes of the thickness of a sample after a compression of $50 \%$ at $70{ }^{\circ} \mathrm{C}$ during $22 \mathrm{~h}$; it is expressed in percent compared to the initial thickness.

\section{Acknowledgements}

The authors would like to thank the Agency for Innovation by Science and Technology in Flanders (IWT project SoPUre), KU Leuven (Methusalem grant CASAS) for financial support.

Keywords: Polyurethane - Foam - Split-phase - Alcoholysis Hydrolysis

[1] J.O. Akindoyo, M.D.H. Beg, S. Ghazali, M. R. Islam, N. Jeyaratnama, A. R. Yuvarajc, RSC Adv. 2016, 6, 114453.

[2] W. Yang, Q. Dong, S. Liu, H. Xie, L. Liu, J. Li, Procedia Environ. Sci. 2012, 16, 167-175.

[3] a) L. R. Mahoney, S. A. Weiner, F. C. Ferris, Environ. Sci. Technol. 1974 8, 135-139; b) J. Gerlock, J. Braslaw, L. R. Mahoney, F. C. Ferris, J. Polym. Sci. Polym. Chem. Ed. 1980, 18, 541-557; c) J. Gerlock, J. Braslaw, M. Zinbo, Ind. Eng. Chem. Process Des. Dev. 1984, 23, 545552; d) O. Kondo, T. Hashimoto, H. Hasegawa, US Pat., 4014809A, 1977; e) W. McElroy, US Pat., 3117940A, 1964; f) M. Sheratte, US Pat. 4162995A, 1979; g) H. Watando, S. Saya, T. Fukaya, S. Fujieda, M. Yamamoto, Polym. Degrad. Stab. 2006, 91, 3354-3359; h) G. Behrendt, B. W. Naber, J. Univ. Chem. Technol. Metall., 2009, 44, 3-23; i) D. Simón, A. M. Borreguero, A. de Lucas, J. F. Rodríguez, Waste Manag. 2018, 76, 147-171; j) D. Simón, J. F. Rodríguez, M. Carmona, A. Serrano, A. M. Borreguero, Chem. Eng. J. 2018, 350, 300-311; k) J. Datta, P. Kopczyńska, D. Simón, J. F. Rodríguez, J. Polym. Environ. 2018, 26, 166-174; I) J. Maioli, J. V. Soares, F. Uliana, T. Valim, C. Francisco, E. Silva Filho, V. Junior, A. Neto, Orbital Electron. J. Chem. 2019, 11, 3341.

[4] a) G. Parinello, D. Thorpe, G. Verhelst, J. F. G. Hopper, M. B. A De Witte, US Pat., 5691389A, 1997; b) C. Molero, A. de Lucas, J. F. Rodríguez, Polym. Degrad. Stab. 2006, 91, 894-901; c) D. Simón, A. de Lucas, J. F. Rodríguez, A. M. Borreguero, Polym. Degrad. Stab. 2016, 133, 119-130.

[5] K. M. Zia, H. N. Bhatti, I. A. Bhatti, React. Funct. Polym. 2007, 67, 675692.

[6] M. Modesti, F. Simioni, R. Munari, N. Baldoin, React. Funct. Polym. 1995 26, 157-165.

[7] a) D. Simón, A. M. Borreguero, A. De Lucas, J. F. Rodríguez, Polym. Degrad. Stab. 2015, 121, 126-136; b) P. J. Trzebiatowska, A. Dzierbicka, N. Kamińska, J. Datta, Polym. Int. 2018, 67, 1368-1377; c) P. J. Trzebiatowska, H. Beneš, J. Datta, React. Funct. Polym. 2019, 139, 2533.

[8] a) M. M. A. Nikje, M. Nikrah, M. Haghshenas, Polym. Bull. 2007, 59, $91-$ 104; b) M. M. A. Nikje, M. Nikrah, Polym. Bull. 2007, 58, 411-423.

[9] D. Simón, A. de Lucas, J. F. Rodríguez, A. M. Borreguero, Polym. Degrad. Stab. 2016, 133, 119-130.

[10] a) G. Schneider, K. Wagner, H. W. Patzelt, US Pat., 4115298A, 1978, b) K. Wagner, M. Dahm, US Pat., 4013625A, 1977.

[11] D. Simón, A. De Lucas, J. F. Rodríguez, A. M. Borreguero, J. Appl. Polym. Sci. 2017, 45087, 1-9

[12] B. Jousseaume, C. Laporte, T. Toupance, J.-M. Bernard, Tetrahedron Lett. 2002, 43, 6305-6307.

[13] a) A. Garofalo, L. Goossens, P. Six, N. Lebegue, P. Depreux, Synth Commun. 2011, 41, 2007-2016; b) E. Reixach, N. Bonet, F. X. Rius-ruiz, S. Wershofen, A. Vidal-Ferran, Ind. Eng. Chem. Res. 2010, 49, 63626366

[14] B. García, S. Aparicio, R. Alcalde, R. Ruiz, M. J. Dávila and J. M. Leal, J. Phys. Chem. B, 2004, 108, 3024-3029.

[15] A. J. Leo, Chem. Rev. 1993, 93, 1281-1306

[16] Ullmann's Polymers and Plastics: Products and Processes, Vol. 3, WileyVCH, Weinheim, 2016, p. 1084

[17] C. Carré, H. Zoccheddu, S. Delalande, P. Pichon, L. Avérous, Eur. Polym J. 2016, 84, 759-769. 


\section{Entry for the Table of Contents}

Split-phase alcoholysis is a promising technique for the recycling of flexible polyurethane (PU) foam, with the potential to achieve a circular use of the polyether polyol and aromatic components. The process was improved by employing new alcoholyzing agents such as diglycerol and a lactam co-reactant, yielding a polyether polyol of high purity suitable for the synthesis of new flexible PU foams.

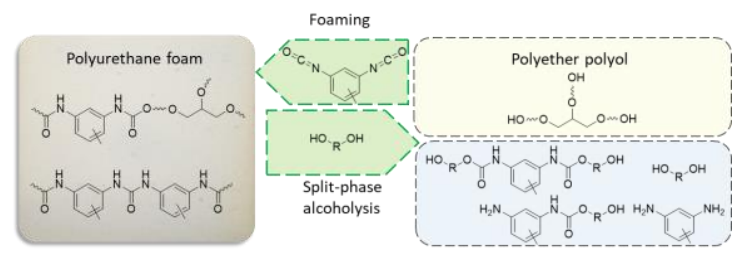

